\title{
Neoadjuvant treatment of pancreatic carcinosarcoma: a case report and review of literature
}

\author{
Chloe S. Lalonde ${ }^{1 \wedge}$, Linyuan Wang ${ }^{2} \wedge$, Brian Quigley ${ }^{2}$, Pretesh Patel ${ }^{3}$, Shishir K. Maithel ${ }^{4}$, \\ Bassel F. El-Rayes ${ }^{5}$, Mehmet Akce ${ }^{5 \wedge}$ \\ ${ }^{1}$ Department of Medicine, Emory University School of Medicine, Atlanta, GA, USA; ${ }^{2}$ Department of Pathology, Emory University School of \\ Medicine, Atlanta, GA, USA; ${ }^{3}$ Department of Radiation Oncology, Winship Cancer Institute, Emory University, Atlanta, GA, USA; ${ }^{4}$ Division of \\ Surgical Oncology, Department of Surgery, Emory University School of Medicine, Atlanta, GA, USA; ${ }^{5}$ Department of Hematology and Medical \\ Oncology, Winship Cancer Institute, Emory University, Atlanta, GA, USA \\ Correspondence to: Mehmet Akce, MD. Department of Hematology and Medical Oncology, Winship Cancer Institute, Emory University School of \\ Medicine, 100 Woodruff Circle, Atlanta, GA 30322, USA. Email: mehmet.akce@emory.edu.
}

\begin{abstract}
Carcinosarcoma of the pancreas is a rare malignancy with high mortality. Diagnosis is based on pathologic demonstration of adjacent malignant epithelial and mesenchymal tissue. Due to inherent limitations of biopsy sampling, tumor heterogeneity is rarely recognized until definitive surgical resection. A 52-year-old woman presented to the emergency department with diarrhea. Abdominal CT imaging showed a $4.1 \times 4.5 \mathrm{~cm}$ mass in the head of the pancreas with intrahepatic and extrahepatic ductal dilation. Endoscopic ultrasound (EUS) confirmed the mass with evidence of superior mesenteric vein involvement. Fine-needle aspiration (FNA) showed adenocarcinoma. After multi-disciplinary tumor board discussion, the patient was treated with four cycles of neoadjuvant of oxaliplatin, irinotecan, fluorouracil, and leucovorin (FOLFIRINOX) followed by 50-55 Gray (Gy) photon radiation with concurrent capecitabine. Pancreaticoduodenectomy was performed after 6 months of neoadjuvant therapy. Pathologic examination revealed carcinosarcoma of the pancreas, with pathological partial response in the resected tumor. Patient has been disease-free for 15 months. Carcinosarcoma of pancreas is a rare clinical entity. There is no established systemic therapy and only two patients, inclusive of this case, have been treated with neoadjuvant chemotherapy. Here we report a case of pancreatic carcinosarcoma treated with neoadjuvant FOLFIRINOX followed by chemoradiation with pathological partial response. Modern treatment approaches for pancreatic ductal adenocarcinoma (PDAC) could be applied to this rare pathology.
\end{abstract}

Keywords: Pancreas; pancreatic; neoadjuvant; carcinosarcoma; case report

Submitted Sep 01, 2021. Accepted for publication Dec 14, 2021.

doi: $10.21037 /$ cco-21-119

View this article at: https://dx.doi.org/10.21037/cco-21-119

\section{Introduction}

Carcinosarcoma of the pancreas is a rare malignancy with poor prognosis that has been identified in the literature in 39 patients since it was first described in a case report in 1951 (1). It is a single tumor consisting of two distinct malignant tissues with both epithelial and mesenchymal morphology. The epithelial component can be adenocarcinoma, squamous cell carcinoma, or basal cell carcinoma, among others. The mesenchymal component can be spindle cell sarcoma, rhabdosarcoma, osteosarcoma, chondrosarcoma, or undifferentiated sarcoma (2). Median overall survival is 6 months (1).

Carcinosarcoma is a separate diagnosis from sarcomatoid

^ ORCID: Chloe S. Lalonde, 0000-0002-6775-3299; Linyuan Wang, 0000-0002-8771-9098; Mehmet Akce, 0000-0003-4747-7722. 
carcinoma, which is more homogenous epithelial tissue that is considered to be spindled, poorly differentiated carcinoma (3). The differentiation is made based on histomorphology. There are three predominant theories regarding the co-occurrence of malignant epithelial and mesenchymal tissues within a discrete tumor. The collision theory posits that the two malignancies are independently arising primaries. The combination theory posits that one stem cell line differentiates into an epithelial cell line and a mesenchymal cell line. The transformation theory profers that a metaplastic change occurs within a tumor cell undergoing epithelial to mesenchymal transition (4).

Although characteristic pre-operative imaging features have been reported (5), carcinosarcoma of the pancreas cannot yet be reliably diagnosed until definitive surgical resection. Patients with pancreatic carcinosarcomas most commonly present with abdominal pain related to mass effect, followed by weight loss, and diarrhea due to compromised pancreatic exocrine function. Jaundice and pruritus can result with biliary obstruction (6). Imaging workup reveals a pancreatic mass. Due to its nonspecific symptoms, radiographic workups are often delayed and patients often present with metastatic or locally advanced disease that is unresectable due to involvement of vasculature. Surgery is the primary treatment modality of pancreatic malignancies. In borderline resectable or locally advanced disease, neoadjuvant systemic therapy could be offered, with the goal of disease control and downstaging to the point of feasible resection (7).

Here we present a case of a 52-year-old woman with borderline resectable pancreatic tumor, diagnosed as adenocarcinoma by fine-needle aspiration (FNA). She was treated with neoadjuvant chemotherapy and chemoradiation prior to definitive surgery. Pathology of the surgical specimen showed pancreatic carcinosarcoma with pathological partial response in the sarcomatous component. We also performed a literature review of reported cases of pancreatic carcinosarcoma, with focus on treatment regimen. We present the following case in accordance with the CARE reporting checklist (available at https://cco.amegroups.com/ article/view/10.21037/cco-21-119/rc).

\section{Case presentation}

A 52-year-old woman with history of Type II diabetes mellitus, hypertension, and hyperlipidemia presented to an outside emergency department with diarrhea. She was found to have abnormal transaminases, hyperbilirubinemia, and computed tomography (CT) imaging of the abdomen showed a $4.1 \times 3.5 \times 4.5 \mathrm{~cm}$ lesion in the head of the pancreas with intrahepatic and extrahepatic ductal dilation (Figure 1), and a $2 \mathrm{~cm}$ liver lesion. Endoscopic ultrasound (EUS) confirmed pancreatic head mass with evidence of portal vein invasion. FNA of the mass showed adenocarcinoma. She was referred to a tertiary academic center.

Physical examination at the initial visit was normal. Family history was notable for pancreatic cancer in her mother, diagnosed at age 61. Endoscopic retrograde cholangiopancreatography (ERCP) with stent placement was performed to relieve biliary obstruction. Magnetic resonance imaging (MRI) of the abdomen showed hypodensity features of the liver lesion more consistent with hemangioma, and no distant metastases. Consensus of multidisciplinary tumor board was to proceed with neoadjuvant chemotherapy for borderline resectable disease and restage. The patient received four cycles (eight biweekly treatments over 4 months) of oxaliplatin, irinotecan, fluorouracil, and leucovorin (FOLFIRINOX). Re-staging scans showed radiologic response to treatment, and the patient continued with 2 months of concurrent chemoradiation. She received $10 \mathrm{MV}$ photon radiation with 50-55 Gray (Gy) to the tumor and 45 Gy to nodal areas over 25 fractions with concurrent capecitabine. Re-staging scans showed a stable pancreatic head mass, with less than 180-degree interface with superior mesenteric vein (Figure 2). The patient underwent pancreaticoduodenectomy after 6 months of neoadjuvant treatment (Figure 3).

Pathology of the specimen showed a $3.6 \mathrm{~cm}$ invasive poorly differentiated carcinosarcoma of the pancreas with both glandular and sarcomatoid components (Figure 4). The carcinosarcoma invaded into the common bile duct, duodenum, and peripancreatic soft tissue. The sarcoma component demonstrated prominent therapy-related changes and patchy malignant osteoid/chondroid matrix depositions (Figures 5,6). A few small foci reminiscent of undifferentiated carcinoma with osteoclast-like giant cells were also identified. Residual cancer burden was graded as a partial response, defined as more than single cell or rare small groups of cancer cells remaining. Lymphovascular invasion and perineural invasion were present. None of the 25 lymph nodes identified were involved by metastatic carcinosarcoma. The overall stage was ypT2ypN0. Pancreatic neck, common bile duct, retroperitoneal, duodenal, and gastric margins were all negative for highgrade dysplasia and carcinoma. Subsequent surveillance CT chest/abdomen/pelvis imaging have shown no evidence of 


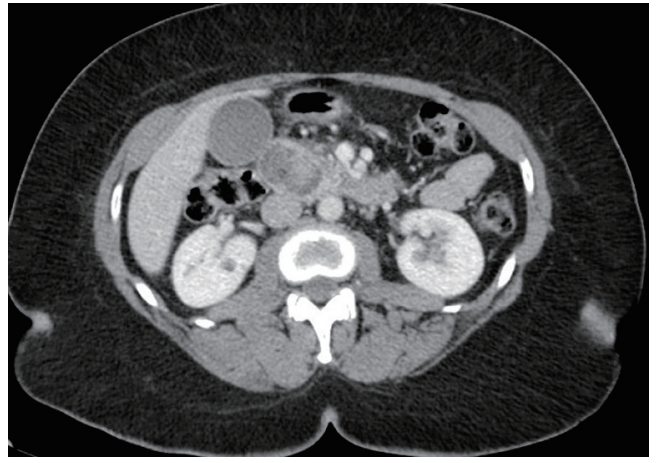

Figure 1 Axial view of computed tomography demonstrating a $4.1 \times 4.5 \mathrm{~cm}$ mass in head of the pancreas with intrahepatic and extrahepatic duct dilation.

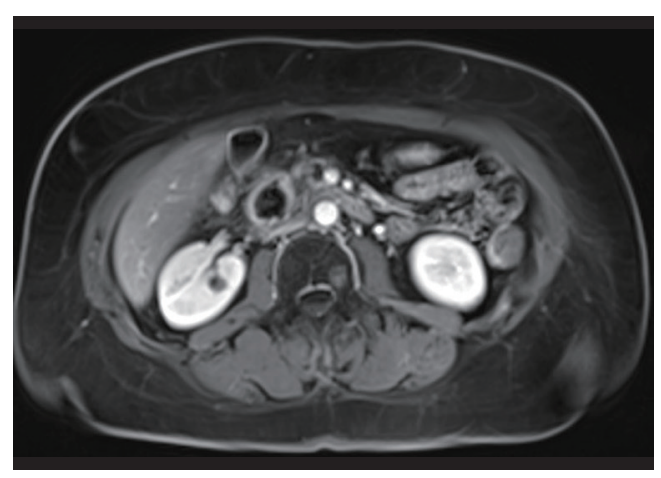

Figure 2 Axial view of MRI showing $2.7 \times 2.6 \mathrm{~cm}$ hypo-enhancing mass in the pancreatic head/uncinate process after neoadjuvant therapy. MRI, magnetic resonance imaging.

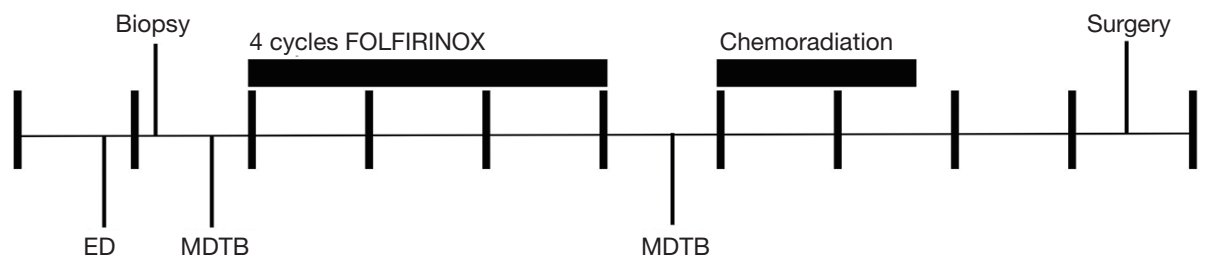

Figure 3 Timeline of treatment course. Weighted lines indicate 1 month time intervals. ED, emergency department; MDTB, multi-disciplinary tumor board; FOLFIRINOX, chemotherapy regimen of oxaliplatin, irinotecan, fluorouracil, and leucovorin.

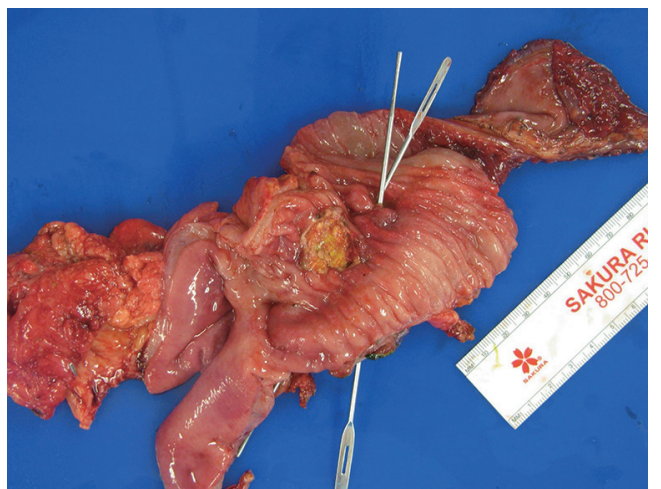

Figure 4 Gross specimen resected during pancreaticoduodenectomy.

disease recurrence. Patient has remained disease free for 15 months since her surgery (Figure 3).

All procedures performed in this study were in accordance with the ethical standards of the institutional and/or national research committee(s) and with the Helsinki Declaration (as revised in 2013). Written informed consent was obtained from the patient for publication of this case report and accompanying images. A copy of the written consent is available for review by the editorial office of this journal.

\section{Discussion}

Carcinosarcoma of the pancreas is a rare clinical entity with no established systemic therapy. Less than 40 case reports comprise the available literature informing treatment courses and patient outcomes, of which only two cases have received a neoadjuvant treatment approach.

To date, systemic treatment for carcinosarcoma of the pancreas has been extrapolated from treatment guidelines for pancreatic ductal adenocarcinoma (PDAC). Pancreatectomy is backbone of curative treatment regimens for localized PDAC. Due to occult presenting symptoms, aggressive metastatic character of disease, and no established screening strategy, only $9 \%$ of patients present with localized disease and 29\% with regional disease, of which in total $15-20 \%$ are resectable (8). Neoadjuvant chemotherapy is used to downsize local and regional disease and achieve complete surgical resection (7), which is associated with improved survival (9). 


\section{Page 4 of 8}

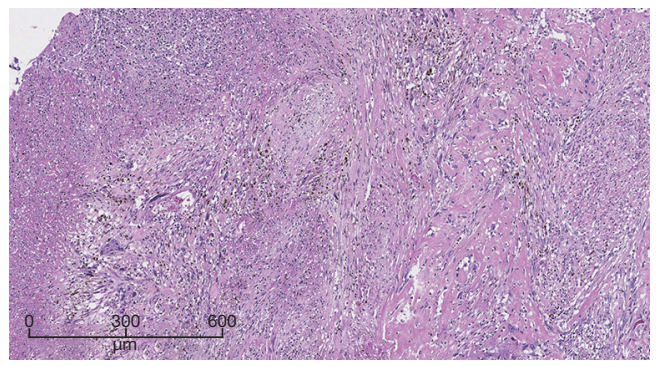

Figure 5 Histopathology slide demonstrating tumor necrosis, hemosiderin treatment effect, and malignant osteoid (hematoxylin and eosin stain).

The two preferred neoadjuvant chemotherapy regimens for PDAC are FOLFIRINOX or gemcitabine and nabpaclitaxel $(6,7)$. Phase II SWOG S1505 trial, which recruited from 2015-2018, directly compared FOLFIRINOX and gemcitabine plus nab-paclitaxel regimens in 102 patients with resectable disease in a perioperative setting. Primary endpoint of 2-year OS showed no difference between the two regimens $(47 \%$ and $48 \%$ for FOLFIRINOX and gemcitabine plus nab-paclitaxel, respectively) (10). Regarding the addition of neoadjuvant radiotherapy, the ALLIANCE A021101 trial neoadjuvant examined neoadjuvant FOLFIRINOX followed by chemoradiation with concurrent capecitabine in a 22-patient feasibility cohort. Of the 15 patients who proceeded to surgery, 7 (46\%) had major pathologic response, defined as $<5 \%$ viable cancer cells at time of surgery (11), compared to the $33 \%$ major pathologic response rate with neoadjuvant chemotherapy alone in SWOG S1505 (12). Data from the full cohort of 134 patients in ALLIANCE 021501 which began accrual in 2017 is eagerly awaited (13). In the adjuvant setting FOLFIRINOX, based on the PRODIGE-24 trial (14), and gemcitabine plus capecitabine, based on the ESPAC-4 trial (15) are established chemotherapy regimens. Emerging data suggest adjuvant therapy following neoadjuvant therapy and resection provides additional survival benefit $(16,17)$.

Although 39 cases of pancreatic carcinosarcoma have been recorded through SEER (1), only 24 case reports were accessible through PubMed for this review (Table 1). In the available literature, 23 of 24 patients underwent surgery. Eight had a tissue biopsy prior to treatment. Five of eight cases with pre-treatment biopsies showed adenocarcinoma alone. Two pre-treatment biopsies demonstrated more than one histology. Eight patients received systemic therapy, two of which, inclusive of our patient, were treated with

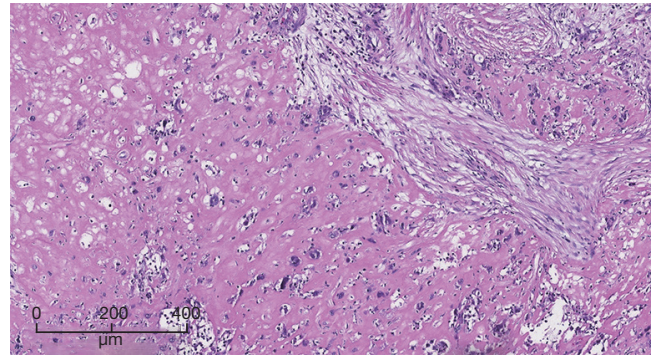

Figure 6 Histopathology showing pleomorphic sarcomatoid cells and osteoid (hematoxylin and eosin stain).

neoadjuvant chemotherapy.

Our patient was treated with neoadjuvant FOLFIRINOX followed by chemoradiation for biopsy-proven PDAC. Pathologic examination at the time of definitive surgical resection revealed carcinosarcoma of the pancreas. Prominent therapy-related changes were seen in the sarcoma component of the tumor. The other case treated with neoadjuvant therapy was a 59-year-old woman who was diagnosed with PDAC by FNA and underwent 3 months of modified FOLFIRINOX before pancreaticoduodenectomy (20). Pathology of the surgical specimen showed moderately differentiated adenocarcinoma and high-grade spindle cell sarcoma with focal chondrosarcoma and myogenic differentiation. Moderate treatment response was noted in the carcinomatous portion. The patient received adjuvant gemcitabine and paclitaxel but rapidly developed metastatic disease, which was biopsied and revealed sarcoma. She died 13 months after diagnosis.

An additional case relevant to present discussion is a 49-year-old woman with history of left oophorectomy who underwent biopsy of distal pancreatic mass during a right salpingo-oophorectomy and total abdominal hysterectomy (4). Biopsy revealed spindle cell sarcoma and adenocarcinoma, consistent with pancreatic carcinosarcoma. The pancreatic mass was unresectable at time of surgery due to involvement of the superior mesenteric artery (SMA). She was treated with gemcitabine and docetaxel with no response, and progressed through second line ifosfamide and doxorubicin. She died 10 months after diagnosis. No posthumous tissue examination was reported (4), and no treatment effect is known.

In this last case, biopsy during laparotomy provided the only known case of pancreatic carcinosarcoma diagnosed prior to surgical resection. Even with the benefit of 
Table 1 Treatment of pancreatic carcinosarcoma cases reported in the literature

\begin{tabular}{|c|c|c|c|c|c|c|c|}
\hline Author & Year & Epi & Biopsy method \& diagnosis & Neo-adjuvant treatment & Surgery & Adjuvant treatment & Survival \\
\hline $\begin{array}{l}\text { Lalonde } \\
\text { (present case) }\end{array}$ & 2021 & $52 \mathrm{~F}$ & $\begin{array}{l}\text { EUS with FNA: } \\
\text { adenocarcinoma }\end{array}$ & $\begin{array}{l}4 \text { cycles FOLFIRINOX, } \\
\text { radiation w/ concurrent } \\
\text { capecitabine }\end{array}$ & $\mathrm{Y}$ & - & >15 months \\
\hline Quinn (18) & 2020 & $42 \mathrm{~F}$ & $\begin{array}{l}\text { Transgastric FNA: } \\
\text { adenocarcinoma }\end{array}$ & - & $\mathrm{Y}$ & $\begin{array}{l}9 \text { cycles gemcitabine } \\
\& \text { paclitaxel, } 11 \text { cycles } \\
\text { FOLFOX }\end{array}$ & 16 months \\
\hline Zhou (19) & 2018 & $44 \mathrm{~F}$ & - & - & $\mathrm{Y}$ & - & $>48$ months \\
\hline Still (20) & 2018 & $59 \mathrm{~F}$ & $\begin{array}{l}\text { EUS with FNA: } \\
\text { adenocarcinoma }\end{array}$ & $\begin{array}{l}6 \text { cycles modified } \\
\text { FOLFIRINOX }\end{array}$ & Y & $\begin{array}{l}1 \text { cycle gemcitabine \& } \\
\text { paclitaxel }\end{array}$ & 10 months \\
\hline Mszyco (3) & 2017 & $85 \mathrm{M}$ & $\begin{array}{l}\text { EUS with FNA: atypical } \\
\text { spindle \& myxoid type sarcoma }\end{array}$ & - & $\mathrm{Y}$ & & 2.5 months \\
\hline Jia (22) & 2017 & $44 \mathrm{~F}$ & - & - & $\mathrm{Y}$ & $\begin{array}{l}8 \text { cycles gemcitabine \& } \\
\text { raltitrexed }\end{array}$ & >31 months \\
\hline Lee (23) & 2015 & $24 \mathrm{~F}$ & - & - & $\mathrm{Y}$ & & - \\
\hline Shi (5) & 2015 & $74 \mathrm{~F}$ & - & - & $\mathrm{Y}$ & & - \\
\hline Oymaci (24) & 2013 & $66 \mathrm{M}$ & $\begin{array}{l}\text { ERCP with brushings: } \\
\text { adenocarcinoma }\end{array}$ & - & $\mathrm{Y}$ & & 20 days \\
\hline Bloomston (29) & 2006 & $67 \mathrm{~F}$ & - & - & $\mathrm{Y}$ & & 4 months \\
\hline Chmiel (30) & 2005 & $47 \mathrm{M}$ & - & - & $\mathrm{Y}$ & - & - \\
\hline Barkatullah (31) & 2005 & $67 \mathrm{~F}$ & $\begin{array}{l}\text { EUS with FNA: poorly } \\
\text { differentiated carcinoma } \\
\text { w/multinucleated giant cells }\end{array}$ & - & $\mathrm{Y}$ & - & 8 months \\
\hline Darvishian (32) & 2002 & $74 \mathrm{M}$ & $\begin{array}{l}\text { ERCP with brushings: } \\
\text { adenocarcinoma }\end{array}$ & - & Y & - & $>4$ months \\
\hline Watanabe (33) & 1997 & $76 \mathrm{M}$ & - & - & $\mathrm{Y}$ & - & 3 months \\
\hline Millis (34) & 1994 & - & - & - & $\mathrm{Y}$ & - & - \\
\hline Takahashi (35) & 1987 & $48 \mathrm{~F}$ & - & - & - & - & $\begin{array}{l}\text { Reported on } \\
\text { autopsy }\end{array}$ \\
\hline Van Damme (36) & 1951 & - & - & - & - & - & - \\
\hline
\end{tabular}

Blank spaces indicate procedure/therapy not performed. Dashed lines indicate information unknown/not available. F, female; M, male; EUS, endoscopic ultrasound; FNA, fine needle aspiration; ERCP, endoscopic retrograde cholangiopancreatography; FOLFIRINOX, chemotherapy regimen of oxaliplatin, irinotecan, fluorouracil, and leucovorin; $\mathrm{Y}$, yes. 


\section{Page 6 of 8}

this diagnosis, sarcoma-directed anthracycline-based chemotherapy was unfortunately ineffective. In the second case, the patient was treated with modified FOLFIRINOX for adenocarcinoma based on available biopsy sample. Treatment effect was seen in the carcinoma component, but the patient died from metastatic sarcoma. The authors posited that chemotherapy may have allowed one cell line to proliferate. In the present case, FOLFIRINOX regimen was selected with available tissue diagnosis of adenocarcinoma, but treatment effect was seen in the sarcomatous portion. The patient has experienced survival of greater than 15 months, which is three times greater than median survival for this pathology. It is not known whether control of either carcinoma or sarcomatous component is more beneficial for overall survival, or whether a unified regimen would confer greater benefit.

Carcinosarcoma of the pancreas is a rare diagnosis with high mortality for which there is no established systemic therapy. Here we add to the literature the second known reported case of borderline resectable pancreatic carcinosarcoma treated with neoadjuvant therapy. Our patient was treated with FOLFIRINOX followed by chemoradiation with capecitabine; treatment effect was seen primarily within the sarcomatous component, and the patient attained survival of greater than 15 months. Modern treatment approaches for PDAC could be applied to this rare pathology.

\section{Acknowledgments}

Funding: None.

\section{Footnote}

Reporting Checklist: The authors have completed the CARE reporting checklist. Available at https://cco.amegroups.com/ article/view/10.21037/cco-21-119/rc

Peer Review File: Available at https://cco.amegroups.com/ article/view/10.21037/cco-21-119/prf

Conflicts of Interest: All authors have completed the ICMJE uniform disclosure form (available at https://cco.amegroups. com/article/view/10.21037/cco-21-119/coif). The authors have no conflicts of interest to declare.

Ethical Statement: The authors are accountable for all aspects of the work in ensuring that questions related to the accuracy or integrity of any part of the work are appropriately investigated and resolved. All procedures performed in this study were in accordance with the ethical standards of the institutional and/or national research committee(s) and with the Helsinki Declaration (as revised in 2013). Written informed consent was obtained from the patient for publication of this case report and accompanying images. A copy of the written consent is available for review by the editorial office of this journal.

Open Access Statement: This is an Open Access article distributed in accordance with the Creative Commons Attribution-NonCommercial-NoDerivs 4.0 International License (CC BY-NC-ND 4.0), which permits the noncommercial replication and distribution of the article with the strict proviso that no changes or edits are made and the original work is properly cited (including links to both the formal publication through the relevant DOI and the license). See: https://creativecommons.org/licenses/by-nc-nd/4.0/.

\section{References}

1. Alhatem A, Quinn PL, Xia W, et al. Pancreatic carcinosarcoma clinical outcome analysis of the national cancer institute database. J Surg Res 2021;259:62-70.

2. Liu Y, Hao H, Guo X, et al. Rare pancreatic carcinosarcoma in a patient with medical history of esophageal cancer: a case report and literature review. Medicine (Baltimore) 2019;98:e15238.

3. Mszyco S, Teng L, Annunziata J, et al. Pancreatic carcinosarcoma: a case report highlighting computed tomography characteristics. Curr Probl Diagn Radiol 2017;46:342-5.

4. Salibay CJ, Rewerska J, Gupta S, et al. Primary carcinosarcoma of the pancreas with CD10-positive sarcoma component. J Investig Med High Impact Case Rep 2017;5:2324709617740906.

5. Shi HY, Xie J, Miao F. Pancreatic carcinosarcoma: first literature report on computed tomography imaging. World J Gastroenterol 2015;21:1357-61.

6. National Comprehensive Cancer Network. Pancreatic adenocarcinoma (Version 1.2021). Available online: https:// www.nccn.org/professionals/physician_gls/pdf/pancreatic. pdf. Accessed February 23, 2021.

7. Brown ZJ, Cloyd JM. Trends in the utilization of neoadjuvant therapy for pancreatic ductal adenocarcinoma. J Surg Oncol 2021;123:1432-40.

8. Raufi AG, Manji GA, Chabot JA, et al. Neoadjuvant 
treatment for pancreatic cancer. Semin Oncol 2019;46:19-27.

9. Fatima J, Schnelldorfer T, Barton J, et al. Pancreatoduodenectomy for ductal adenocarcinoma: implications of positive margin on survival. Arch Surg 2010;145:167-72.

10. Sohal DPS, Duong M, Ahmad SA, et al. Efficacy of perioperative chemotherapy for resectable pancreatic adenocarcinoma: a phase 2 randomized clinical trial. JAMA Oncol 2021;7:421-7.

11. Katz MH, Shi Q, Ahmad SA, et al. Preoperative modified FOLFIRINOX treatment followed by capecitabinebased chemoradiation for borderline resectable pancreatic cancer: Alliance for clinical trials in oncology trial A021101. JAMA Surg 2016;151:e161137.

12. Ahmad SA, Duong M, Sohal DPS, et al. Surgical outcome results from SWOG S1505: a randomized clinical trial of mFOLFIRINOX versus gemcitabine/nab-paclitaxel for perioperative treatment of resectable pancreatic ductal adenocarcinoma. Ann Surg 2020;272:481-6.

13. Katz MHG, Ou FS, Herman JM, et al. Alliance for clinical trials in oncology (ALLIANCE) trial A021501: preoperative extended chemotherapy vs. chemotherapy plus hypofractionated radiation therapy for borderline resectable adenocarcinoma of the head of the pancreas. BMC Cancer 2017;17:505.

14. Conroy T, Hammel P, Hebbar M, et al. FOLFIRINOX or gemcitabine as adjuvant therapy for pancreatic cancer. $\mathrm{N}$ Engl J Med 2018;379:2395-406.

15. Fenocchio E, Filippi R, Lombardi $\mathrm{P}$, et al. Is there a standard adjuvant therapy for resected pancreatic cancer? Cancers (Basel) 2019;11:1547.

16. Powell-Brett S, Pande R, Roberts KJ. Achieving 'marginal gains' to optimise outcomes in resectable pancreatic cancer. Cancers (Basel) 2021;13:1669.

17. Kamarajah SK, White SA, Naffouje SA, et al. Adjuvant chemotherapy associated with survival benefit following neoadjuvant chemotherapy and pancreatectomy for pancreatic ductal adenocarcinoma: a population-based cohort study. Ann Surg Oncol 2021;28:6790-802.

18. Quinn PL, Ohioma D, Jones AMK, et al. Treatment of rare and aggressive pancreatic carcinosarcoma. ACG Case Rep J 2020;7:e00379.

19. Zhou X, Li M, Wang P, et al. Carcinosarcoma colliding osteosarcoma of the pancreas: a rare case report of multiple clonal originated pancreatic tumors. Int J Clin Exp Pathol 2018;11:1746-53.

20. Still SA, Becerra CR, Clement-Kruzel SE, et al. Locally advanced carcinosarcoma of the pancreas. Proc (Bayl Univ Med Cent) 2018;31:210-2.

21. Ruess DA, Kayser C, Neubauer J, et al. Carcinosarcoma of the pancreas: case report with comprehensive literature review. Pancreas 2017;46:1225-33.

22. Jia Z, Zhang K, Huang R, et al. Pancreatic carcinosarcoma with rare long-term survival: case report and review of the literature. Medicine (Baltimore) 2017;96:e5966.

23. Lee J, Hyun JJ, Lee HS. A rare cause of abdominal pain by pancreatic mass in a young female patient. Carcinosarcoma of the pancreas. Gastroenterology 2015;149:e3-5.

24. Oymaci E, Argon A, Coşkun A, et al. Pancreatic carcinosarcoma: case report of a rare type of pancreatic neoplasia. JOP 2013;14:212-5.

25. Zhu WY, Liu TG, Zhu H. Long-term recurrence-free survival in a patient with pancreatic carcinosarcoma: a case report with a literature review. Med Oncol 2012;29:140-3.

26. Kim HS, Joo SH, Yang DM, et al. Carcinosarcoma of the pancreas: a unique case with emphasis on metaplastic transformation and the presence of undifferentiated pleomorphic high-grade sarcoma. J Gastrointestin Liver Dis 2011;20:197-200.

27. Shen ZL, Wang S, Ye YJ, et al. Carcinosarcoma of pancreas with liver metastasis combined with gastrointestinal stromal tumour of the stomach: is there a good prognosis with the complete resection? Eur J Cancer Care (Engl) 2010;19:118-23.

28. Gelos M, Behringer D, Philippou S, et al. Pancreatic carcinosarcoma. Case report of multimodal therapy and review of the literature. JOP 2008;9:50-5.

29. Bloomston M, Chanona-Vilchis J, Ellison EC, et al. Carcinosarcoma of the pancreas arising in a mucinous cystic neoplasm. Am Surg 2006;72:351-5.

30. Chmiel B, Wodołazski A, Kozaczka A. Carcinosarcoma of the pancreas--case report and literature review. Wiad Lek 2005;58:243-6.

31. Barkatullah SA, Deziel DJ, Jakate SM, et al. Pancreatic carcinosarcoma with unique triphasic histological pattern. Pancreas 2005;31:291-2.

32. Darvishian F, Sullivan J, Teichberg S, et al. Carcinosarcoma of the pancreas: a case report and review of the literature. Arch Pathol Lab Med 2002;126:1114-7.

33. Watanabe $M$, Miura $H$, Inoue $H$, et al. Mixed osteoclastic/ pleomorphic-type giant cell tumor of the pancreas with ductal adenocarcinoma: histochemical and immunohistochemical study with review of the literature. 
Page 8 of 8

Pancreas 1997;15:201-8.

34. Millis JM, Chang B, Zinner MJ, et al. Malignant mixed tumor (carcinosarcoma) of the pancreas: a case report supporting organ-induced differentiation of malignancy. Surgery 1994;115:132-7.

Cite this article as: Lalonde CS, Wang L, Quigley B, Patel P, Maithel SK, El-Rayes BF, Akce M. Neoadjuvant treatment of pancreatic carcinosarcoma: a case report and review of literature. Chin Clin Oncol 2022;11(1):8. doi: 10.21037/cco-21-119
Lalonde et al. Neoadjuvant treatment of pancreatic carcinosarcoma

35. Takahashi K, Wakayama M, Asaji A, et al. An autopsy case of a so-called carcinosarcoma of the pancreas. Gan No Rinsho 1987;33:1481-7.

36. Van Damme J, Snoeks T. Carcinosarcoma of the body of the pancreas. Acta Gastroenterol Belg 1951;14:106-13. 